\title{
Vesicoureteral Reflux and Renal Scarring in Children with Acute Pyelonephritis: the Role of Late 6-month Dimercaptosuccinic Acid Renal Scan
}

\author{
Kyeong Eun Oh, M.D. \\ Hyung Eun Yim, M.D., Ph.D. \\ Kee Hwan Yoo, M.D., Ph.D. \\ Department of Pediatrics, Korea \\ University College of Medicine, Seoul, \\ Korea
}

Corresponding author:

Hyung Eun Yim, M.D., Ph.D.

Department of Pediatrics, Korea University

Ansan Hospital, Korea University College

of Medicine, 123 Jeokgeum-ro, Danwon-

gu, Ansan 15355, Republic of Korea

Tel: +82-31-412-5096

Fax: +82-31-405-8591

E-mail: he-yim@hanmail.net

Received: 30 August 2020

Revised: 21 September 2020

Accepted: 27 September 2020
Purpose: The aim of this study is to evaluate the clinical utility of late 6-month dimercapto-succinic acid (DMSA) renal scan in predicting vesicoureteral reflux (VUR) and long-lasting renal scars in children with first acute pyelonephritis (APN). Methods: A retrospective case study of children admitted with APN from January 2010 to July 2017 was performed. The study included patients with voiding cystourethrography (VCUG) and acute and late 6-month DMSA scan. We analyzed the clinical, laboratory and imaging findings of patients with and without late cortical defects at 6 months and those with or without VUR.

Results: Among 145 children with APN, 50 (34.5\%) had cortical defects on the late DMSA renal scan and 60 (41.4\%) showed VUR. Thirteen of 38 (34.2\%) children undergoing 18-month DMSA renal scan showed a long-lasting renal scars. Compared with children without late cortical defects, patients with late 6-month cortical defects had a higher incidence of VUR and long-lasting renal scars, and relapse of UTI (all $P<0.05$ ). In a multivariable analysis, both high-grade VUR and relapse of UTI were independently correlated with the presence of late 6 -month cortical defects $(P<0.05)$. Late cortical defects and relapse of UTI were also associated with the presence of VUR $(P<0.05)$. Only the late 6 -mo cortical defects was an independent predictor of long-lasting renal scars in children with APN $(P<0.05)$.

Conclusion: An abnormal late 6-month DMSA renal scan may be useful in identifying VUR and long-lasting renal scars in children diagnosed with APN.

Key words: Renal scarring, Acute pyelonephritis, Vesicoureteral reflux, Dimercaptosuccinic acid renal scan

\section{Introduction}

Urinary tract infection (UTI) is the most common bacterial infection in childhood and approximately $10 \%$ to $15 \%$ of cases lead to renal scarring ${ }^{1)}$. Vesicoureteral reflux (VUR) is a relatively common urological anomaly in children, leading to renal scarring and ultimately chronic/end-stage kidney disease $^{2-4)}$. However, the diagnosis of UTI is sometimes challenging because of nonspecific clinical features, especially in infants ${ }^{5}$. Variable imaging studies are used to effectively evaluate and manage UTI, renal VUR, and renal scarring $^{6}$. Each imaging modality has advantages and limitations, which makes it difficult to determine the best imaging tool for the evaluation of UTI in 
children. Renal bladder ultrasonography (RBUS) is a noninvasive, inexpensive and radiation-free tool for diagnosing UTI but results vary depending on the examiner. The accuracy of RBUS also depends on the children's age and is low in children aged younger than 1 year ${ }^{7)}$. Voiding cystourethrography (VCUG) is the most reliable modality available to evaluate VUR; however, it is invasive and expensive, and is also associated with the risk of radiation exposure to patients. VCUG also requires urethral catheterization and carries the risk of iatrogenic UTI both with (2\%) and without (6-22\%) antibiotic prophylaxis ${ }^{8-10)}$. The ${ }^{99 \mathrm{~m}} \mathrm{Tc}$-dimercaptosuccinic acid (DMSA) renal scan is the most sensitive technique available for the detection of acute cortical defects and long-lasting renal scars but it also increases the risk of radiation exposure ${ }^{11)}$.

Currently, two major approaches are available for assessing and managing febrile UTI in children. The American Academy of Pediatrics (AAP) clinical practice guidelines for the diagnosis and management of febrile UTIs recommend RBUS for the detection of serious complications in acute phase ${ }^{12}$. However, DMSA renal scan is not recommended as part of routine evaluation in acute febrile UTI. VCUG is indicated if RBUS reveals hydronephrosis, renal scarring, or other findings that suggest either high-grade VUR or obstructive uropathy ${ }^{13)}$. In contrast to the bottomup approach, the top-down approach recommends DMSA renal scan during the first febrile UTI and a late DMSA scan if the first scan is positive ${ }^{14)}$. DMSA renal scan is the clinical gold standard for identifying acute cortical defects or renal scarring. Therefore, it is recommended during acute and follow-up phases of febrile UTIs. VCUG is indicated when DMSA scan reveals acute cortical defects ${ }^{15)}$. This finding is highly debated due to the radiation burden ${ }^{16,17)}$.

Given the controversy associated with the current practice guidelines for evaluating UTI in children, we analyzed the clinical indications for DMSA renal scan and VCUG in children with febrile UTI. In the present study, we hypothesized that renal cortical defects in the late 6-month DMSA scan predict VUR and long-lasting renal scars in children with febrile UTI. The aim of this study is to investigate the clinical utility of late DMSA scan in detecting VUR and long-lasting renal scars in children with first episode of APN.

\section{Materials and methods}

\section{Study population and design}

A retrospective case analysis of children admitted with first febrile UTI from January 2010 to July 2017 was performed. A total of 492 patients aged between 1 month and 12 years were included. The inclusion criteria were: i) cortical defects in acute DMSA scan, and ii) treatment with both VCUG and late 6-month DMSA scan. The exclusion criteria were: i) underlying congenital anomalies of kidney and urinary tract except VUR and uretero-pelvic junction stenosis, ii) acute kidney injury (AKI), and iii) underlying chronic kidney disease (CKD).

\section{Definition}

Febrile UTI was defined by the presence of pyuria, positive urine culture, and fever $>38^{\circ} \mathrm{C}$. Urine culture was defined as positive if $\geq 5 \times 10^{4}$ colony forming units $/ \mathrm{mL}$ of a single species ${ }^{18)}$ were detected in a sample obtained via urethral catheterization for non toilet-trained infants and midstream clean-catch specimens or a sterile bag for toilettrained children. APN was defined in patients with cortical defects on acute DMSA renal scan. Late cortical defects was defined as cortical defects on late DMSA scan 6 months after acute febrile UTI. Long lasting renal scars were defined as cortical defects on repeated DMSA scan at least 18 months after acute febrile UTI. Cortical defects were defined by the presence of focal or diffuse areas of decreased cortical uptake, with preservation of the renal contour ${ }^{1)}$. High-grade VUR was defined as grade IV-V VUR and low-grade VUR was defined as grade I-III VUR in VCUG.

\section{Laboratory and radiological assessments}

We divided patients into two groups according to the presence of late cortical defects or VUR, respectively. Clinical, laboratory and imaging findings were analyzed in patients with or without late 6-month cortical defects and in those with or without VUR. Clinical findings included sex, age and fever duration before the initiation of treatment for UTI. Laboratory findings included initial white blood cell (WBC) counts and C-reactive protein (CRP) levels. 


\section{Statistics}

Continuous variables are expressed as mean \pm standard deviation and categorical variables are described using frequencies and proportions. Differences between populations were analyzed using Chi-square test and MannWhitney $U$ test. To identify the factors that predict late cortical defects, VUR, high-grade VUR, and long-lasting renal scars, factors correlating significantly with those of univariable logistic regression analyses $(P<0.05)$ were entered into multivariable logistic regression analyses ${ }^{19)}$. We calculated the odds ratios including 95\% confidence interval (CI), and $P$ values $<0.05$ were considered statistically significant. Data were analyzed using IBM SPSS software version 20.0 for Windows (SPSS Inc., Chicago, IL, USA).

\section{Results}

\section{Patient characteristics}

Among 492 children with febrile UTIs, a total of 145 patients with APN were finally enrolled in the present study. A total of 269 patients were found without APN in the acute DMSA scan. Patients who were not subjected to acute DMSA $(n=1)$ scan were excluded. Patients diagnosed with underlying congenital anomalies of kidney and urinary tract included 2 cases of kidney agenesis, 1 case of ectopic kidney, 1 case of renal hypoplasia, 1 case of horseshoe kidney, and 1 case of duplicated kidney. Children without $\operatorname{VCUG}(\mathrm{n}=1)$ and late 6-month DMSA scan $(\mathrm{n}=70)$ were excluded from those diagnosed with APN (n=216) (Fig. 1). The mean age of enrolled patients was $7.7 \pm 16.0$ months, with a preponderance of males (66.9\%). The mean fever duration was $2.3 \pm 2.2$ days. Seventy-four children (51.0\%) had hydronephrosis and 48 children (33.1\%) had APN on RBUS (51 hydronephrosis only, 25 APN only, 23 both hydronephrosis and APN). Among children with APN, 50 patients (34.5\%) showed cortical defects in late 6-month DMSA scan (old defect 44/50, new defect 6/50). Among 145 patients, DMSA scans at least 18 months after acute febrile UTI were performed in 38 cases, and 13 children (34.2\%) showed long-lasting renal scars (old defect 12/13, new defect 1/13). VUR was found in 60 of 145 patients (41.4\%). Among them, 46 cases were high-grade (grade IV-V). During a mean follow-up of $14.5 \pm 17.9$ months, 43 children (29.7\%) showed UTI relapse.

\section{Comparison of patients with and without late 6- month cortical defects}

Among 145 patients with APN, 50 patients were assigned to the late cortical defects group and 95 patients were assigned to the group with early defects alone. The mean age was higher in the group with late 6-month cortical defects, compared to the group with early defects alone $(P<0.001)$.

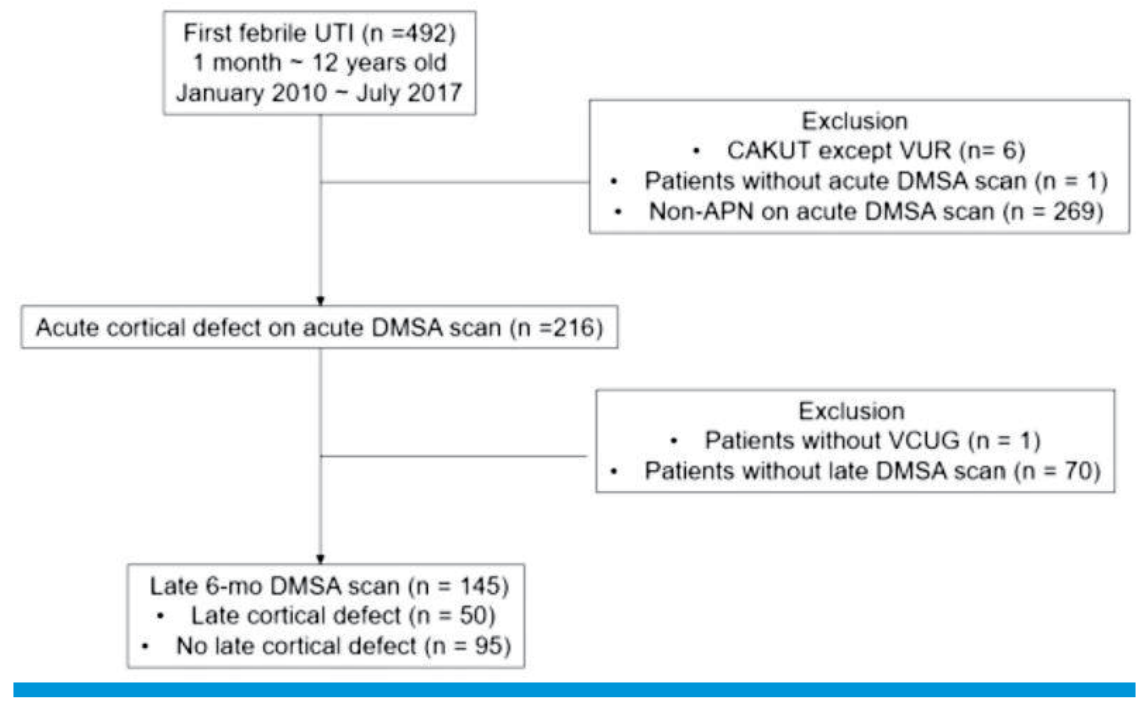

Fig. 1. Study design and patient enrollment. UTI, Urinary tract infection; CAKUT, congenital anomaly of kidney and urinary tract; VUR, vesicoureteral reflux; DMSA, dimercapto- succinic acid; APN, acute pyelonephritis; VGUG, voiding cystourethrography. 
Sex distribution and fever duration did not differ between the two groups. Hydronephrosis and APN on RBUS were more frequently found in the group of patients with late cortical defects, compared to the group with early defects alone $(P<0.05)$. VUR and high-grade VUR (IV-V) were also frequently detected in the group with late cortical defects (both $P<0.05$ ). The proportions of patients with longlasting renal scars ( $\geq 18$ months) and UTI relapse were higher in the group with late cortical defects (both $P<0.05$ ). Serum WBC and CRP levels were also higher in the group with late cortical defects than in those with early defects (both $P<0.05$ ) (Table 1).

\section{Comparison of patients with and without VUR}

Among 145 patients with APN, 60 patients had VUR. There were no differences of age, gender distribution, and fever duration in children with and without VUR. While the proportion of hydronephrosis on RBUS was not different between the two groups, that of sonographic APN was higher in patients with VUR than in those without VUR

Table 1. Clinical and Laboratory Data according to the Presence of Late Cortical Defects in 6-month DMSA Scans of Patients with Acute Pyelonephritis

\begin{tabular}{|c|c|c|c|}
\hline & $\begin{array}{l}\text { Late cortical } \\
\text { defect }(N=50)\end{array}$ & $\begin{array}{l}\text { Early defect } \\
\text { only }(\mathrm{N}=95)\end{array}$ & $p$ \\
\hline Female, n (\%) & $12 / 50(24.0)$ & 36/95 (37.9) & $0.091^{*}$ \\
\hline Age (months) & $10.4 \pm 22.1$ & $6.3 \pm 11.6$ & $<0.001^{\dagger}$ \\
\hline Fever duration (days) & $2.3 \pm 2.6$ & $2.4 \pm 2.0$ & $0.272^{\dagger}$ \\
\hline Hydronephrosis on US, n (\%) & $33 / 50(66.0)$ & $41 / 95(55.4)$ & $0.009^{*}$ \\
\hline APN on US, n (\%) & $23 / 50(46.0)$ & 25/95 (26.3) & $0.017^{*}$ \\
\hline VUR, n (\%) & $35 / 50(70.0)$ & 25/95 (26.3) & $<0.001^{*}$ \\
\hline Low-grade VUR (I-III), n (\%) & $7 / 50(14.0)$ & $7 / 95(7.4)$ & $0.199 *$ \\
\hline High-grade VUR (IV-V), n (\%) & $28 / 50(56.0)$ & 18/95 (18.9) & $<0.001^{*}$ \\
\hline Renal scar at 18 months, $\mathrm{n}(\%)$ & $11 / 21(52.4)$ & $2 / 17(11.8)$ & $0.009^{*}$ \\
\hline Old defect, n (\%) & $11 / 11(100.0)$ & $1 / 2(50.0)$ & $0.015^{*}$ \\
\hline New defect, n (\%) & $0 / 11(0.0)$ & $1 / 2(50.0)$ & $0.015^{*}$ \\
\hline Relapse, n (\%) & $25 / 50(50.0)$ & 18/95 (18.9) & $<0.001^{*}$ \\
\hline Relapse within 6 mo, n (\%) & $20 / 25(80.0)$ & $9 / 18(50.0)$ & $<0.001^{*}$ \\
\hline Relapse within 18 mo, n (\%) & $24 / 25(96.0)$ & 16/18 (88.8) & $<0.001^{*}$ \\
\hline Follow-up duration (months) & $21.7 \pm 23.5$ & $11.0 \pm 13.0$ & $0.001^{\dagger}$ \\
\hline WBC at diagnosis $(/ \mu \mathrm{L})$ & $18,126 \pm 6,598$ & $16,137 \pm 6,423$ & $0.050^{\dagger}$ \\
\hline CRP at diagnosis (mg/dL) & $10.0 \pm 6.9$ & $7.3 \pm 5.9$ & $0.014^{\dagger}$ \\
\hline
\end{tabular}

Data are presented as mean \pm SD (or interquartile range) or numbers (\%). *Chi-square test.

${ }^{\dagger}$ Mann-Whitney U test

Abbreviations: DMSA, dimercapto-succinic acid; US, ultrasonography; APN, acute pyelonephritis; VUR, vesicoureteral reflux; WBC, white blood cells; CRP, C-reactive protein.
$(P<0.05)$. Abnormal sonographic findings including hydronephrosis and APN were higher in patients with $\operatorname{VUR}(P<$ $0.05)$. The VUR group showed a higher incidence of late 6 month cortical defects, compared to children without VUR $(P<0.05)$. However, the prevalence of long-lasting renal scars did not differ between children with and without VUR among those diagnosed with APN. The follow-up duration was longer in the VUR group and the relapse of UTI was higher in the VUR group $(P<0.05)$. Serum CRP level was higher in the VUR group $(P<0.05)$ while serum WBC concentration was not different between the two groups (Table 2).

\section{Univariable and multivariable logistic regression analyses}

The univariable logistic regression analysis revealed a correlation of hydronephrosis and APN on RBUS, highgrade VUR, UTI relapse for 18 months after APN, and high serum CRP levels with the presence of late 6-month cortical defects, respectively. However, in the multivariable analysis, the presence of high-grade VUR and relapse of UTI within 6 months independently predicted the incidence of late cortical defects $(P<0.05)$ (Table 3$)$. A diagnosis

Table 2. Clinical and Laboratory Data according to the Presence of VUR

\begin{tabular}{|c|c|c|c|}
\hline & $\operatorname{VUR}(n=60)$ & no VUR $(n=85)$ & $P$ \\
\hline Female, n (\%) & $21 / 60(35.0)$ & $27 / 85(31.8)$ & $0.683^{*}$ \\
\hline Age (months) & $10.2 \pm 21.9$ & $8.2 \pm 17.5$ & $0.501^{\dagger}$ \\
\hline Fever duration (days) & $2.8 \pm 2.7$ & $2.3 \pm 2.0$ & $0.132^{\dagger}$ \\
\hline Hydronephrosis on US, n (\%) & $36 / 60(60.0)$ & $38 / 85(44.7)$ & $0.070^{*}$ \\
\hline APN on US, n (\%) & $26 / 60(43.3)$ & $22 / 85(28.1)$ & $0.028^{*}$ \\
\hline Abnormal findings on US, $n$ (\%) & $47 / 60(78.3)$ & $52 / 85(61.1)$ & $0.045^{*}$ \\
\hline $\begin{array}{l}\text { Late cortical defect at } 6 \text { months, } \\
\mathrm{n}(\%)\end{array}$ & $35 / 60(58.3)$ & 15/85 (17.6) & $<0.001^{*}$ \\
\hline Renal scar at 18 months, $n$ (\%) & $11 / 29(37.9)$ & $2 / 9(22.2)$ & $0.386^{*}$ \\
\hline Follow-up duration (months) & $23.1 \pm 22.8$ & $11.6 \pm 15.4$ & $<0.001^{*}$ \\
\hline Relapse, n (\%) & $32 / 60(53.3)$ & $11 / 85(12.9)$ & $<0.001^{*}$ \\
\hline Relapse within 6 months, n (\%) & $23 / 60(38.3)$ & $6 / 11(54.5)$ & $<0.001^{*}$ \\
\hline Relapse within 18 months, n (\%) & $31 / 60(51.6)$ & 9/11 (81.8) & $<0.001^{*}$ \\
\hline WBC at diagnosis $(/ \mu \mathrm{L})$ & $17,404 \pm 7,106$ & $16,458 \pm 5,856$ & $0.598^{\dagger}$ \\
\hline CRP at diagnosis (mg/dL) & $10.0 \pm 7.2$ & $7.3 \pm 5.4$ & $0.014^{\dagger}$ \\
\hline
\end{tabular}

Data are presented as mean \pm SD (or interquartile range) or numbers (\%). ${ }^{*}$ Chi-square test.

${ }^{\dagger}$ Mann-Whitney $U$ test.

Abbreviations: VUR, vesicoureteral reflux; US, ultrasonography; APN, acute pyelonephritis; WBC, white blood cells; CRP, C-reactive protein. 
of APN on RBUS, abnormal findings on RBUS, late cortical defects, relapse of UTI within 6 months, and increased serum CRP levels showed a positive correlation with the presence of VUR. Late cortical defects, UTI relapse within 6 months, and high serum CRP were also independently correlated with the presence of VUR $(P<0.05)$ (Table 4$)$. Late cortical defects and UTI relapse within 6 months independently predicted the presence of high-grade VUR $(P<0.05)$. Hydronephrosis and high levels of serum CRP were also associated with high-grade VUR in univariable analyses; however, they were not independent predictors of high-grade VUR (Table 5). The incidence of APN on RBUS, late 6-month cortical defects, and relapse of UTI within 6 months post-APN correlated with long-lasting renal scarring in the univariable analyses. However, only the late 6-month cortical defects were independently asso- ciated with long-lasting renal scars $(P<0.05)$. Both low- and high-grade VUR did not predict the emergence of longlasting renal scars (Table 6).

\section{Discussion}

In this study, we found that an abnormal late 6-month DMSA renal scan after first UTI was useful in identifying VUR and long-lasting renal scars in children with APN. Late 6-month cortical defects and UTI relapse within 6 months were independently associated with the presence of high-grade VUR as well as VUR. Conversely, high-grade VUR and relapse of UTI independently predicted the incidence of late cortical defects at 6 months. Late 6-month cortical defects also independently predicted long-lasting

Table 3. Univariable and Multivariable Logistic Regression Analyses of Factors Underlying Late Cortical Defect

\begin{tabular}{|c|c|c|c|c|}
\hline \multirow{2}{*}{ Variables } & \multicolumn{2}{|c|}{ Univariable } & \multicolumn{2}{|c|}{ Multivariable } \\
\hline & Odds ratio $(95 \% \mathrm{Cl})$ & P & Odds ratio $(95 \% \mathrm{Cl})$ & P \\
\hline Female & $0.518(0.240-1.118)$ & 0.094 & & \\
\hline Age & $1.016(0.994-1.038)$ & 0.163 & & \\
\hline Fever duration & $0.998(0.854-1.167)$ & 0.985 & & \\
\hline Hydronephrosis on US & $2.557(1.254-5.212)$ & 0.010 & $1.993(0.888-4.473)$ & 0.094 \\
\hline APN on US & $2.385(1.161-4.898)$ & 0.018 & 2.027 (0.878-4.678) & 0.098 \\
\hline Low-grade VUR (I-III) & $2.047(0.675-6.206)$ & 0.206 & & \\
\hline High-grade VUR (IV-V) & $5.444(2.550-11.623)$ & $<0.001$ & 3.167 (1.357-7.391) & 0.008 \\
\hline Relapse within 6 months & $6.370(2.617-15.508)$ & $<0.001$ & 3.618 (1.349-9.702) & 0.011 \\
\hline WBC at diagnosis & $1.000(1.000-1.000)$ & 0.083 & & \\
\hline CRP at diagnosis & $1.068(1.012-1.128)$ & 0.018 & $1.038(0.976-1.103)$ & 0.238 \\
\hline
\end{tabular}

Abbreviations: Cl, confidence interval; US, ultrasonography; APN, acute pyelonephritis; VUR, vesicoureteral reflux; WBC, white blood cells; CRP, C-reactive protein.

Table 4. Univariable and Multivariable Logistic Regression Analyses of Factors associated with VUR

\begin{tabular}{|c|c|c|c|c|}
\hline \multirow{2}{*}{ Variables } & \multicolumn{2}{|c|}{ Univariable } & \multicolumn{2}{|c|}{ Multivariable } \\
\hline & Odds ratio $(95 \% \mathrm{Cl})$ & $P$ & Odds ratio $(95 \% \mathrm{Cl})$ & $P$ \\
\hline Female sex & $1.157(0.574-2.329)$ & 0.684 & & \\
\hline Age & $1.017(0.994-1.041)$ & 0.150 & & \\
\hline Fever duration & $1.171(0.999-1.372)$ & 0.051 & & \\
\hline Hydronephrosis on US & $1.855(0.949-3.627)$ & 0.071 & & \\
\hline APN on US & $2.190(1.083-4.430)$ & 0.029 & $1.217(0.477-3.103)$ & 0.681 \\
\hline Abnormal findings on US & $2.294(1.080-4.873)$ & 0.031 & $1.415(0.539-3.713)$ & 0.481 \\
\hline Late cortical defect at 6 months & $6.533(3.062-13.941)$ & $<0.001$ & $3.920(1.708-8.996)$ & 0.001 \\
\hline Relapse for within 6 months & $8.185(3.073-21.80)$ & $<0.001$ & $5.324(1.828-15.502)$ & 0.002 \\
\hline WBC & $1.000(1.000-1.000)$ & 0.368 & & \\
\hline CRP & $1.085(1.026-1.148)$ & 0.005 & $1.065(1.001-1.132)$ & 0.047 \\
\hline
\end{tabular}

Abbreviations: Cl, confidence interval; US, ultrasonography; APN, acute pyelonephritis; WBC, white blood cells; CRP, C-reactive protein. 
Table 5. Univariable and Multivariable Logistic Regression Analyses of Variables Correlated with High-grade VUR

\begin{tabular}{|c|c|c|c|c|}
\hline \multirow{2}{*}{ Variables } & \multicolumn{2}{|c|}{ Univariable } & \multicolumn{2}{|c|}{ Multivariable } \\
\hline & Odds ratio $(95 \% \mathrm{Cl})$ & P & Odds ratio $(95 \% \mathrm{Cl})$ & P \\
\hline Female sex & $0.720(0.336-1.544)$ & 0.399 & & \\
\hline Age & $0.993(0.968-1.018)$ & 0.567 & & \\
\hline Fever duration & $1.014(0.866-1.187)$ & 0.862 & & \\
\hline Hydronephrosis on US & $2.344(1.135-4.838)$ & 0.021 & $1.366(0.450-4.148)$ & 0.582 \\
\hline APN on US & $1.699(0.819-3.522)$ & 0.154 & & \\
\hline Abnormal findings on US & $2.453(1.065-5.652)$ & 0.035 & $1.344(0.379-4.769)$ & 0.647 \\
\hline Delayed cortical defect at 6 months & $5.444(2.550-11.62)$ & $<0.001$ & $3.157(1.368-7.287)$ & 0.007 \\
\hline Relapse within 6 months & $6.263(2.602-15.08)$ & $<0.001$ & $3.935(1.496-10.345)$ & 0.005 \\
\hline WBC & $1.000(1.000-1.000)$ & 0.323 & & \\
\hline CRP & $1.074(1.016-1.136)$ & 0.011 & $1.057(0.995-1.122)$ & 0.074 \\
\hline
\end{tabular}

Abbreviations: Cl, confidence interval; US, ultrasonography; APN, acute pyelonephritis; WBC, white blood cells; CRP, C-reactive protein.

Table 6. Univariable and Multivariable Logistic Regression Analyses of Variables associated with Long-lasting Renal Scar Formation

\begin{tabular}{|c|c|c|c|c|}
\hline \multirow{2}{*}{ Variables } & \multicolumn{2}{|c|}{ Univariable } & \multicolumn{2}{|c|}{ Multivariable } \\
\hline & Odds ratio $(95 \% \mathrm{Cl})$ & $P$ & Odds ratio $(95 \% \mathrm{Cl})$ & $P$ \\
\hline Female & $0.533(0.116-2.456)$ & 0.420 & & \\
\hline Age & $0.969(0.908-1.034)$ & 0.338 & & \\
\hline Fever duration & $0.766(0.491-1.194)$ & 0.239 & & \\
\hline Hydronephrosis on US & $1.477(0.377-5.785)$ & 0.576 & & \\
\hline APN on US & $4.781(1.125-20.319)$ & 0.034 & $3.326(0.615-18.003)$ & 0.163 \\
\hline Cortical defect at 6 months & $8.250(1.498-45.429)$ & 0.015 & $7.333(1.106-48.612)$ & 0.039 \\
\hline Low-grade VUR (I-III) & $0.468(0.082-2.667)$ & 0.392 & & \\
\hline High-grade VUR (IV-V) & $2.864(0.694-11.824)$ & 0.146 & & \\
\hline Relapse within 6 months & $10.56(2.167-51.420)$ & 0.004 & $7.066(0.994-50.230)$ & 0.051 \\
\hline WBC at diagnosis & $1.000(1.000-1.000)$ & 0.474 & & \\
\hline CRP at diagnosis & $1.036(0.931-1.154)$ & 0.513 & & \\
\hline
\end{tabular}

Abbreviations: Cl, confidence interval; US, ultrasonography; APN, acute pyelonephritis; VUR, vesicoureteral reflux; WBC, white blood cells; CRP, C-reactive protein.

renal scars persisting longer than 18 months. These findings suggest that the relapse of UTI, high-grade VUR, and late 6-month cortical defects are correlated with each other in children with APN, and that the cortical defects in the late 6-month DMSA scan may predict high-grade VUR and long-lasting renal scars formation in children with their first APN.

UTI results in long-lasting renal scarring in approxima-

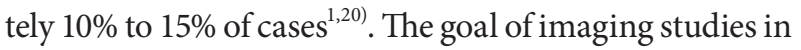
children with UTIs is to identify possible urinary tract abnormalities that may predispose children to additional recurrent UTIs and renal scarring. In the present study, we found that $35 \%$ of patients with APN developed late cortical defects at 6 months after the initial episode of UTI and 65\% of patients with APN experienced resolution of the renal defects. Approximately $33 \%$ of children who underwent
DMSA renal scan more than 18 months later showed longlasting renal scars, and VUR was found in $41.4 \%$ patients with APN. There were 43 children (29.7\%) who had experienced UTI relapse. Among these children, $67.4 \%$ had experienced relapse within 6 months after initial UTI and 93\% had experienced relapse within 18 months after initial UTI. The proportion of patients developing long-lasting renal scars, VUR and UTI relapse was consistent with other studies. Lin et $\mathrm{al}^{21)}$ reported that about $38-57 \%$ children diagnosed with APN develop long-lasting renal scarring. Among children who had UTI, between $25 \%$ and $40 \%$ were found to show $\mathrm{VUR}^{22)}$. The incidence of recurrent UTI in children has been reported to vary from 10 to $30 \%$ in other studies ${ }^{23,24)}$. Since most of the acute cortical lesions disappear in children with febrile UTIs, it is necessary to reconsider acute DMSA scans for all children with febrile 
UTIs as part of routine evaluation recommended by the current top-down approach ${ }^{2025)}$. However, it is apparent that the incidence of long-lasting renal scarring and VUR is relatively high in children diagnosed with their first APN. In a retrospective case analysis of 103 children $<2$ years of age with first UTI, Swerkersson et al reported the relationship between late DMSA scan and VUR or longlasting renal scars in children ${ }^{26)}$. Children were divided into 2 groups according to the findings of late DMSA renal scan performed at least 90 days after the acute UTI. There were no differences between groups regarding sex or age; however, the initial CRP level and incidence of VUR was higher in the group with renal damage during the late DMSA scan. In a follow-up DMSA scan after a minimum of 2 years, long-lasting renal scars developed in $19.4 \%$ of children with late cortical defects. In another study, DMSA scans were acquired 4-6 months after the APN in children and nearly half of the patients carried one or more late renal scars. The distribution of sex, CRP level and leukocytosis did not differ according to the presence of renal scars; however, VURs were more frequently found in children with renal scars ${ }^{27)}$. In the present study, abnormal sonographic findings including both hydronephrosis and APN, the frequency of VUR, long-lasting renal scars, UTI relapse, and higher levels of initial CRP was greater in children with late 6-month cortical defects, compared with those without late cortical defects. High-grade VUR and UTI relapse were found to be independent risk factors for late 6-month cortical defects. While the significance of acute DMSA renal scan appears to be limited, the late DMSA scan is recommended for children with recurrent UTIs and/or VUR.

According to the AAP guidelines, RBUS is preferred as the initial imaging tool for evaluating UTI in children. However, the usefulness of ultrasonography in detecting renal cortical defects and VUR is disputed. In the present study, APN was detected via renal sonography only in 33\% of children with APN who were evaluated with a DMSA renal scan. Hydronephrosis was found only in $60 \%$ of children with VUR, and the incidence of hydronephrosis did not differ between the VUR and non-VUR groups. While the frequency of abnormal sonographic findings including hydronephrosis and APN was higher in the VUR group, the difference was not apparently elevated. Consistent with our study, abnormal RBUS findings such as pye- localyceal fullness or increased parenchymal echogenecity were not correlated with cortical defects detected via DMSA renal scan in 425 children with $\mathrm{APN}^{7}$. In a retrospective case review of 130 children with first UTI, Alshamsan et al ${ }^{28)}$ showed that the sensitivity, specificity, positive and negative predictive values of RBUS for predicting VUR were $50 \%, 76.9 \%, 52.6 \%$ and $75 \%$, respectively, and the results of an abnormal RBUS did not alter the management of patients with febrile UTI. In our present study, APN and abnormal findings on RBUS, late 6-month cortical defects, long-lasting renal scars, relapse of UTI, and higher initial CRP were correlated with VUR in univariable logistic regression analyses. Hydronephrosis detected only in renal sonography was not associated with the presence of VUR. In multivariable logistic regression analyses, late 6-month cortical defects and UTI relapse were independent risk factors for VUR and high-grade VUR, respectively. Therefore, it is questionable whether VCUG is indicated only in patients with abnormal findings on RBUS, as suggested by the AAP guidelines. In one study comparing RBUS and late 6-month DMSA scan in febrile UTI patients, the sensitivity of abnormal RBUS and late 6-month DMSA scan for the diagnosis of high-grade VUR was $50 \%$ and $87.5 \%$, respectively ${ }^{29)}$. Thus, it is unclear whether RBUS has robust sensitivity for the detection of APN and VUR in children with febrile UTI. The VCUG tests based on RBUS finding (bottom-up approach) require further validation and refinement.

Moreover, children showing late 6-month cortical defects were at a high risk for the development of long-lasting renal scars in the present study. Although the presence of APN in RBUS, late 6-month cortical defects, and UTI relapse within 6 months after APN were correlated with longlasting renal scars in the univariable analyses, only late cortical defects was independently associated with longlasting renal scars. The relapse of UTI was a potential risk factor for long-lasting renal scars $(P=0.051)$; however, due to the small number of patients, the results apparently lack reliability. These findings suggest that late DMSA scan may be more beneficial than other imaging studies in predicting the emergence of long-lasting renal scars in children with febrile UTIs.

In summary, late 6-month cortical defects and VUR, which can be independently predicted in children with 
APN, and recurrent UTI, may be associated with the presence of late cortical defects and VUR. Renal cortical defects in late 6-month DMSA scan may also independently predict the persistence of long-lasting renal scars in children with APN. APN on RBUS does not appear to predict the incidence of acute cortical defects established with DMSA renal scan and hydronephrosis on RBUS may not be correlated with the presence of VUR in children with APN. Thus, there may be some limitations in determining VCUG tests based on abnormal RBUS according to the current AAP guidelines ${ }^{12}$. The late DMSA renal scan may be better than initial renal sonography for predicting VUR, especially if remnants of cortical defects are found in the renal scan 6 months later after APN. When patients or their caregivers refuse or hesitate to perform VCUG, the late DMSA scan is a handy tool in determining the performance of VCUG. Late DMSA renal scan is also recommended for patients with VUR or with UTI relapse within 6 months after first febrile UTI. If the late DMSA scan reveals a cortical defects in children with first febrile UTI, a long-term follow-up of patients for at least 18 months is required to evaluate patient recovery.

This study has some limitations. First, it is a small retrospective study conducted in a single center and involves a small number of patients undergoing 18-mo DMSA scans due to follow-up loss. In the future, larger, multicenter, prospective studies are needed to elucidate the role of late DMSA renal scan in predicting VUR and permanent renal scarring in children with febrile UTIs. Second, there may be a selection bias because not all patients with febrile UTI were enrolled and only patients with both late DMSA scan and VCUG findings were selected as subjects. Third, the 6and 18-mo DMSA scans revealed old and new cortical defects, which cannot be defined as simply late cortical defects or long-lasting renal scars.

In conclusion, the presence of cortical defects in late 6month DMSA renal scan may independently predict the presence of VUR, high-grade VUR, and long-lasting renal scars in children with their first febrile UTI.The relapse of UTI, high-grade VUR and late cortical defects might be closely associated with APN in children. Acute DMSA renal scan can be omitted in a few patients with febrile UTIs while late renal scan might be needed in other highrisk children. Further studies are needed to develop tailored and individualized management plans for children with their first febrile UTIs.

\section{Acknoledgments}

This study was approved by the institutional review board (IRB), and the consent was waived due to the nature of the retrospective study [IRB number 2018AS0122].

\section{Conflict of interest}

This research did not receive any specific grant from funding agencies in the public, commercial, or not-forprofit sectors. There were no conflicts of interest relevant to this article.

\section{ORCID IDs}

Hyung Eun Yim https://orcid.org/0000-0001-9805-9278

Keong Eun Oh https://orcid.org/0000-0003-4938-9996

Kee Hwan Yoo https://orcid.org/0000-0001-6490-4293

\section{References}

1. Pokrajac D, Sefic-Pasic I, Begic A. Vesicoureteral reflux and renal scarring in infants after the first febrile urinary tract infection. Med Arch 2018;72:272-5.

2. Nino F, llari M, Noviello C, Santoro L, Ratsch IM, Martino A, et al. Genetics of vesicoureteral reflux. Curr Genomics 2016;17:70-9.

3. Hains DS, Cohen HL, McCarville MB, Ellison EE, Huffman A, Glass $S$, et al. Elucidation of renal scars in children with vesicoureteral reflux using contrast-enhanced ultrasound: A pilot study. Kidney Int Rep 2017;2:420-4.

4. Montini G, Tullus K, Hewitt I. Febrile urinary tract infections in children. N Engl J Med 2011;365:239-50.

5. Murakami N, Kawada JI, Watanabe A, Arakawa T, Kano T, Suzuki T, et al. Ureteral dilatation detected in magnetic resonance imaging predicts vesicoureteral reflux in children with urinary tract infection. PLoS One 2018;13:e0209595.

6. Luk WH, Woo YH, Au-Yeung AW, Chan JC. Imaging in pediatric urinary tract infection: a 9-year local experience. AJR Am J Roentgenol 2009;192:1253-60. 
7. Nickavar A, Safaeian B, Biglari Abhari M. Radiologic and clinical evaluation of children with first febrile urinary tract infection. Int J Pediatr Adolesc Med 2015;2:24-8.

8. Prasad MM, Cheng EY. Radiographic evaluation of children with febrile urinary tract infection: bottom-up, top-down, or none of the above? Adv Urol 2012;2012:716739.

9. Riccabona M. Imaging in childhood urinary tract infection. Radiol Med 2016;121:391-401.

10. Lee LC, Lorenzo AJ, Koyle MA. The role of voiding cystourethrography in the investigation of children with urinary tract infections. Can Urol Assoc J 2016;10:210-4.

11. Supavekin S, Surapaitoolkorn W, Pravisithikul N, Kutanavanishapong S, Chiewvit S. The role of DMSA renal scintigraphy in the first episode of urinary tract infection in childhood. Ann Nucl Med 2013;27:170-6.

12. Subcommittee On Urinary Tract Infection. Reaffirmation of AAP clinical practice guideline: The diagnosis and management of the initial urinary tract infection in febrile infants and young children 2-24 months of age. Pediatrics 2016;138:e20163026.

13. Kaufman J, Temple-Smith M, Sanci L. Urinary tract infections in children: an overview of diagnosis and management. BMJ Paediatr Open 2019;3:e000487.

14. Preda I, Jodal U, Sixt R, Stokland E, Hansson S. Normal dimercaptosuccinic acid scintigraphy makes voiding cystourethrography unnecessary after urinary tract infection. J Pediatr 2007;151:5814.

15. Kobayashi Y, Mishina H, Michihata N, Miyasaka M, Takayama Jl. Indication for voiding cystourethrography during first urinary tract infection. Pediatr Int 2019;61:595-600.

16. De Palma D. Radionuclide tools in clinical management of febrile UTI in children. Semin Nucl Med 2020;50:50-5.

17. O'Reilly SE, Plyku D, Sgouros G, Fahey FH, Ted TS, Frey EC, et al. A risk index for pediatric patients undergoing diagnostic imaging with (99m)Tc-dimercaptosuccinic acid that accounts for body habitus. Phys Med Biol 2016;61:2319-32.

18. Subcommittee on urinary tract infection $\mathrm{SCoQI}$, Roberts KB. Urinary tract infection: clinical practice guideline for the diagnosis and management of the initial UTI in febrile infants and children 2 to 24 months. Pediatrics 2011;128:595-610.

19. Kleinman LC, Norton EC. What's the Risk? A simple approach for estimating adjusted risk measures from nonlinear models including logistic regression. Health Serv Res 2009;44:288-302.

20. Pohl HG, Belman AB. The "top-down" approach to the evaluation of children with febrile urinary tract infection. Adv Urol 2009: 783409 .

21. Lin KY, Chiu NT, Chen MJ, Lai CH, Huang JJ, Wang YT, et al. Acute pyelonephritis and sequelae of renal scar in pediatric first febrile urinary tract infection. Pediatr Nephrol 2003;18:362-5.

22. Cleper R, Krause I, Eisenstein B, Davidovits M. Prevalence of vesicoureteral reflux in neonatal urinary tract infection. Clin Pediatr 2004:43:619-25.

23. Tewary K, Narchi H. Recurrent urinary tract infections in children: Preventive interventions other than prophylactic antibiotics. World J Methodol 2015;5:13-9.

24. Conway PH, Cnaan A, Zaoutis T, Henry BV, Grundmeier RW, Keren R. Recurrent urinary tract infections in children: risk factors and association with prophylactic antimicrobials. JAMA 2007;298: 179-86.

25. Williams G, Craig JC. Long-term antibiotics for preventing recurrent urinary tract infection in children. Cochrane Database Syst Rev 2019;4:CD001534.

26. Swerkersson S, Jodal U, Sixt R, Stokland E, Hansson S. Urinary tract infection in small children: the evolution of renal damage over time. Pediatr Nephrol 2017;32:1907-13.

27. Ehsanipour F, Gharouni M, Rafati AH, Ardalan M, Bodaghi N, Otoukesh H. Risk factors of renal scars in children with acute pyelonephritis. Braz J Infect Dis 2012;16:15-8.

28. Alshamsam L, Al Harbi A, Fakeeh K, Al Banyan E. The value of renal ultrasound in children with a first episode of urinary tract infection. Ann Saudi Med 2009;29:46-9.

29. Wongbencharat K, Tongpenyai Y, Na-Rungsri K. Renal ultrasound and DMSA screening for high-grade vesicoureteral reflux. Pediatr Int 2016;58:214-8. 